\title{
Air Pollution around Schools and Poorer Student Health and Academic Performance: A Case of Dhaka, Bangladesh
}

\author{
Nusrat Jahan \\ University of Dhaka, Dhaka, BANGLADESH \\ ${ }^{*}$ Corresponding Contact: \\ Email: njp26@hotmail.com
}

Manuscript Received: 11 Dec 2019 - Revised: 22 Feb $2020 \quad$ - Accepted: 01 March 2020

\begin{abstract}
Dhaka is one of the most vulnerable cities of the world to the adverse effects of air pollution and variables. Children of Dhaka are the most affected group of people to any crucial change in any climatic change, i.e., air pollution. Exposing children to any environmental pollutants during the times of their growth can lead to longlasting health problems, dysfunction, and disease. The location of the schools can increase their exposure. In such, a survey has been conducted on the extent of air pollution from industrial sources around different schools in Dhaka to find out whether air pollution threatens children's health and academic success. We found that schools in the highest air polluted areas had the poorer attendance rate indicates poor health-and the highest proportions of students who are not performing up to their potential in educational testing standards. However, Dhaka and some other cities do not require officials considering a site for a new school to analyze its air quality. The survey result shows that such requirements are needed. For schools already in existence, we recommend that their environmental quality should be examined and improved to save our future generation.
\end{abstract}

Keywords: Children, Air quality, Pollutants, Particulate matter, Dhaka

This article is is licensed under a Creative Commons Attribution-NonCommercial 4.0 International License.

Attribution-NonCommercial (CC BY-NC) license lets others remix, tweak, and build upon work non-commercially, and

although the new works must also acknowledge \& be non-commercial.

\section{INTRODUCTION}

There are more than fifty thousand school children in North City Corporation in Dhaka. Are these schools safe and healthy places for children to grow, play, and learn? Or are exposing children to unhealthy pollution? Children are known to be more vulnerable than adults to the effects of any pollution. Exposure to environmental pollutants during main times of physiological development can lead to long-lasting physiological problems. Children's lung functioning is not fully developed until the age. Compared to adults, they breathe in the highest levels of polluted air relative to their age and spend more time outside when air pollution level is higher. And because of differences in the 
rate of metabolism, mouthing habits-such as the tendency to put their hands and objects in their mouths-and respiratory rates, children are often exposed to higher levels of different pollutants. Moreover, children have no choice about where they live or go to school, as it solely depends on their parent's overall income and other sociological impacts. Childhood is a critical period for physical development. Researchers have shown that children exposed to air pollution perform worse on cognitive functioning tests and have impaired to any health function and lower IQ levels compared with other children. High levels of Carbon monoxide-a common air pollutant, "decreases of 6.71, 7.37 and 8.61 points in quantitative, working memory, and gross motor areas, respectively," towards the children who are exposed to it.

Similarly, children with high levels of exposure to nitrogen dioxide and other pollutants in 10 micrometers or less in the air-a standard used by the Environmental Protection Agency (EPA) to measure air quality-perform significantly worse on Psychological tests. For example - they have decreased ability to perform well on both communicable and non-communicable intelligence and memory tests, such as the Kaufman Brief Intelligence Test and the Wide Range Assessment of Memory, and Learning.

Hence, School siting policies should protect children from their vulnerability to environmental pollution. However, many Cities do not have any school siting policies. According to a survey in 2016, there is no city prohibit or severely restrict school districts from siting schools on or near sources of pollution or hazards that might pose a risk to children's health. However, few schools have policies suggesting that officials "avoid" siting schools on or near specified natural environmental hazards, or "consider" those hazards when selecting school sites. This article aims at contributing to some of these knowledge gaps by generating research evidence on the nature of vulnerability of children in urban areas by exploring children's perceptions and experiences of air pollution in Dhaka, Bangladesh. The objectives of the article are to find out socio-economic and physical conditions of school children in the city between the age of 5 and 15 years.

- Which pollution events children identify as hazards in Dhaka?

- Whether their perceptions vary by variables such as household income, age, gender, etc.?

- What the children identify as evident impacts of increased air pollution on them?

- What are their suggestive actions to reduce the effect and to manage the risks?

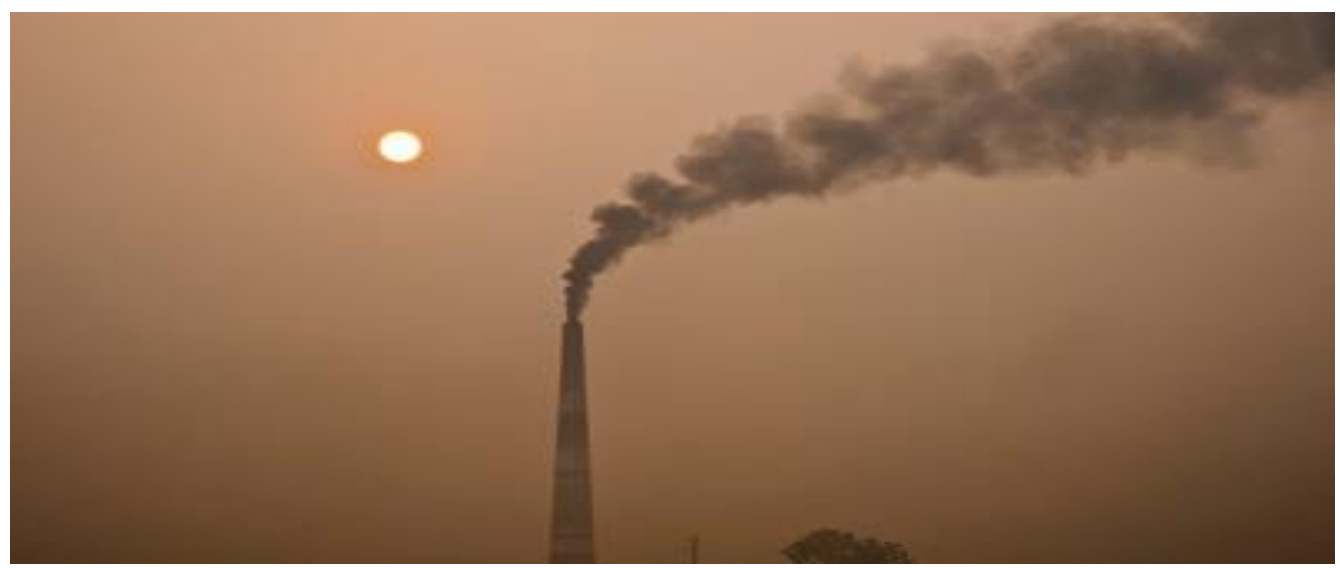

Figure 1: Polluted Air that we inhale in Dhaka city 


\section{The Objectivity of the study}

To determine whether there is a link between concentrations of PM2.5 and PM10 with changes in respiratory symptoms, lung function and which led to lower academic performance of the children in Dhaka City. The study conducted on baseline survey followed by the assessment of health and educational impact of air pollution among school children of this city.

\section{Methodology}

According to the 'Convention of the Rights of the Child' population under the age of 18 is considered to be children. In any research, children's perspectives are often overlooked for different reasons. To survey as a group they are considered to be difficult. Moreover, stringent ethical approval processes make working with children is also time-consuming. Often scientists identify children as a similar group and fail to take into account the key variables such as their age, social class, gender, and ethnicities when collecting data for projects. Also, the disrespectful attitudes of adults, parents, and researchers towards children's views and opinions restrict incorporating them in research. However, despite lacking's, the response of children began to be generally accepted as a principle towards the end twentieth century. Children's perspectives represent their experience, perceptions, and understanding of life and world which, is influenced by biological, psychological, psychological, and social factors. At first, I examined air pollution concentrations from industrial and other pollutant sources within several kilometers of 3 schools in North Dhaka City and collected data according to their percentage of attendance, illness related to air pollution, and how this pollution affects their academic performance.

Table 1: School distribution Asthmatic, Control and academic performance due to air pollution

\begin{tabular}{|l|c|c|c|c|}
\hline $\begin{array}{l}\text { Name of the } \\
\text { school }\end{array}$ & $\begin{array}{c}\text { Breathing } \\
\text { difficulties/Asthmatic }\end{array}$ & $\begin{array}{c}\text { Under } \\
\text { control }\end{array}$ & Absenteeism & $\begin{array}{c}\text { Fall in academic } \\
\text { performances }\end{array}$ \\
\hline $\begin{array}{l}\text { Gulshan High } \\
\text { school ( National } \\
\text { curriculum) }\end{array}$ & $60 \%$ & $30 \%$ & $15 \%$ & $40 \%$ \\
\hline $\begin{array}{l}\text { Chittagong } \\
\text { Grammar School } \\
\text { (Cambridge) }\end{array}$ & $55 \%$ & $20 \%$ & $10 \%$ & $30 \%$ \\
\hline $\begin{array}{l}\text { Sir John Wilson } \\
\text { School (Cambridge) }\end{array}$ & $50 \%$ & $20 \%$ & $10 \%$ & $30 \%$ \\
\hline
\end{tabular}

\section{Sampling}

In three schools that situated in the North part of Dhaka city (High risk areas of air pollution) from where the baseline survey was carried out. The central Air Quality Monitoring Station of the Department of Environment is within five-kilometers of the schools. The AQMP data of this station would represent the air quality state of the selected schools. The participants for this baseline survey were based on all students from class 3 to 8 of these schools (ages between 7-15 years).

\section{Data Collection}

For the survey based on 'The International Study of Asthma and Allergies in Childhood (ISAAC)' questionnaire modified structured questions were selected. In three participating schools an assessment was conducted. 


\section{DatA ANALYSIS}

Data obtained in the baseline survey were analyzed to identify students with high exposer to the polluted air linked with their overall health and educational outcomes.

\section{Particulate and Weather Data}

Corresponding data about particulates (PM10 and PM2.5) of the relevant period was collected from the Air Quality Management Project (AQMP) of the Department of Environment. From the Department of Metrology, relevant metrological data (maximum, minimum, and average daily temperature, relative humidity, and wind speed) was obtained.

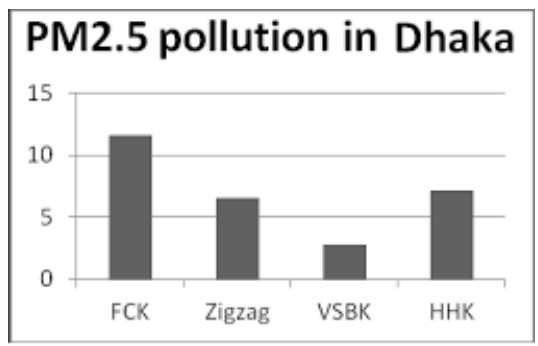

Figure 2: PM2.5 pollution in Dhaka

\section{Air Pollution}

Contamination substances in the atmosphere caused by different pollutants are playing a vital role in air pollution. Often the amount of the released particles is very high in a specific locality, so the effects are more prominent. The main sources of air pollution are CFC gases and the burning of solid waste. A new source of air pollution is thinner the ozone layer in the atmosphere above Antarctica, coupled with growing evidence of global ozone depletion. Through acid rain air pollution hurts the living organisms.

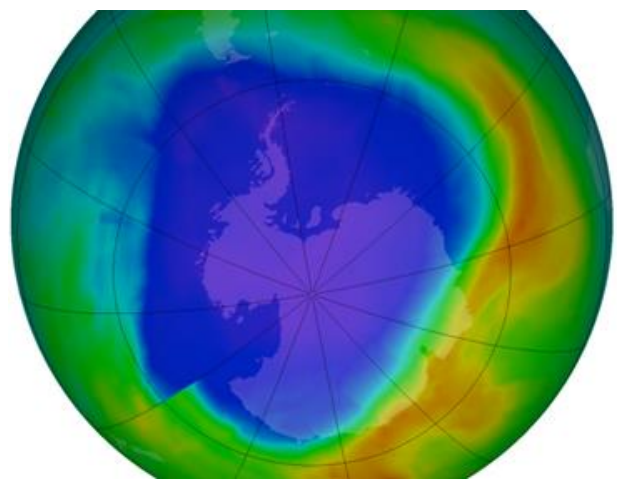

Figure 3: Ozone layer above Antarctica

\section{Description of the Dhaka City}

Dhaka is one of the major cities of the world and rapid growth of the urban population in recent times. The public health is in alarming position in Dhaka city due to air pollution. In the winter of 2017-18, air pollution of Dhaka city became the severest when lead in the air was reported higher than in the atmosphere of any other place in the world. Over a period, air pollution worsens day by day in Dhaka city and led to the proclamation of National Ambient Air Quality Standards in Bangladesh in 2018. 
To find the impact of auto-exhaust on air quality of Dhaka city in the year 2017-18, several surveys have been conducted. It is identified that transportation, fuel quality, and brick field emission are the core reasons of air pollution in Dhaka city.

The risk to health may be greater to exposure to air pollution both, the indoor and outdoor which identified during this study. For the first time, the indoor air pollution level of Dhaka city has also measured periodically. The brick field emission level data have also presented. In this paper the results of an investigation on air quality of Dhaka city have been assessed and put forward some recommendations.
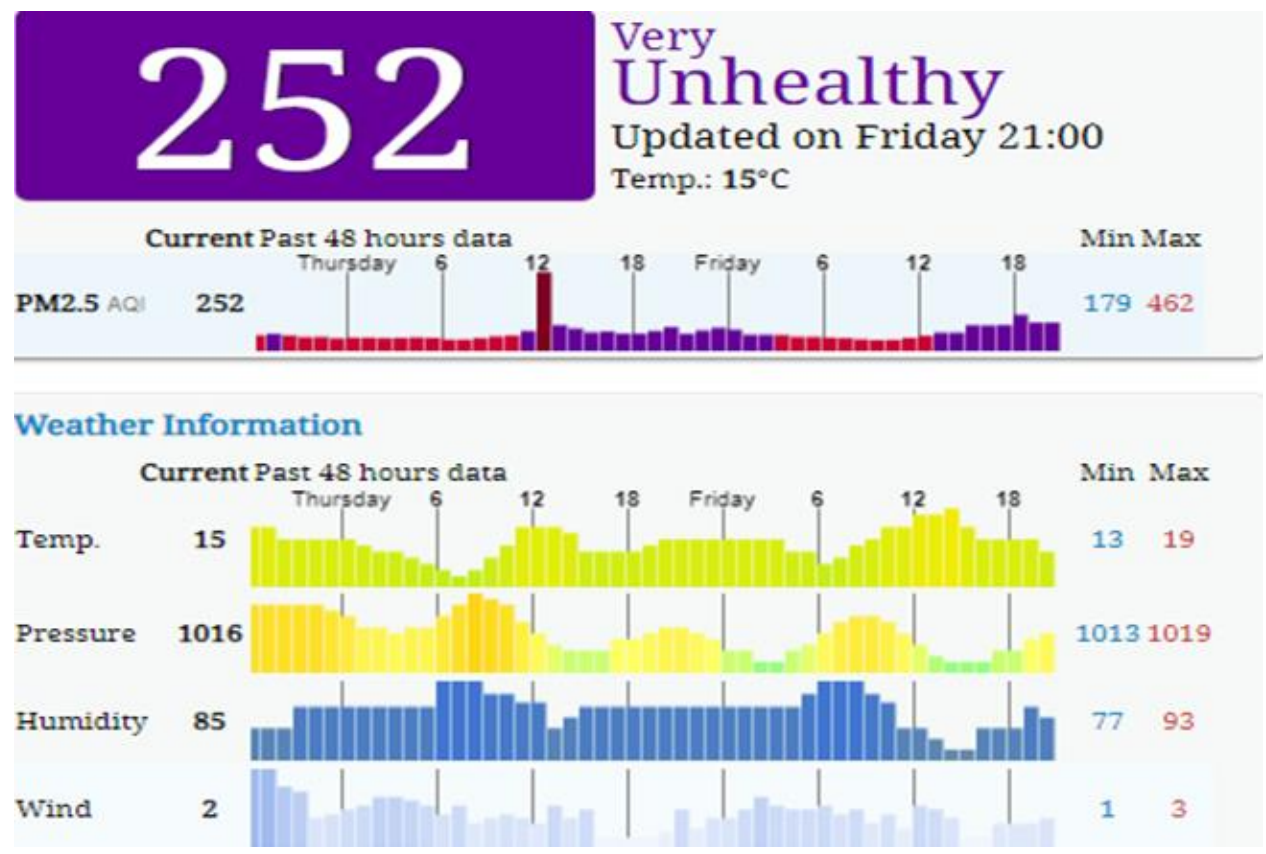

Figure 4: Air quality index

\section{Reasons for air pollution in Dhaka}

Air pollution in the capital city Dhaka has gone higher than Delhi and killing thousands prematurely each year. According to the Department of Environment (DoE), the density of airborne particulate matter (PM) reaches 463 micrograms per cubic meter $(\mathrm{mcm})$ in the city during the December-March period the highest level in the world. Delhi follows Dhaka with 383 and $360 \mathrm{mcm}$, respectively. An estimated, thousands of premature deaths, as well as several million cases of pulmonary, respiratory, and neurological and heart diseases are attributed to the poorest air quality in Dhaka, according to the Air Quality Management Project (AQMP), funded by the government and the World Bank.

Motor air pollution is a vital cause of respiratory diseases in urban Bangladesh. If pregnant mothers come across excessive pollution, it may cause premature or fetus death of their unborn children. According to the National Institute of Diseases of Chest and Hospital (NIDCH), nearly seven million people in Bangladesh suffer from asthma; more than half of them are children. Cases of children suffering from bronchitis and chronic cough have vigorous in recent years. Children breathe more air relative to their lung size than adults. They spend maximum time outdoors, often during midday and afternoons when pollution levels are generally highest. WHO air quality guidelines (2015) recommend a 
maximum acceptable PM level of $20 \mathrm{mcm}$; cities with $70 \mathrm{mcm}$ are considered as highly polluted. Airborne lead is the worst of the harmful PMs.

Table 2: Vehicle population, utilization, and fuel economy in Dhaka, 2016 (Source: European Economic Commission; Dhaka Urban Transport Project Working Papers)

\begin{tabular}{|c|c|c|c|c|}
\hline & $\begin{array}{c}\text { Vehicle } \\
\text { Populatio } \\
\mathbf{n}\end{array}$ & $\begin{array}{c}\text { Annual } \\
\text { Utilization } \\
(\mathbf{k m} / \mathbf{y r})\end{array}$ & $\begin{array}{c}\text { Total Annual Vehicles } \\
\mathbf{k m s} \text { (millions) }\end{array}$ & $\begin{array}{c}\text { Fuel economy } \\
(\mathbf{k m} / \mathbf{l})\end{array}$ \\
\hline Cars \& Taxis & 42,000 & 19,200 & 806.4 & 8.0 \\
\hline $\begin{array}{c}\text { Jeep, Station } \\
\text { Wagon, Micro } \\
\text { Bus }\end{array}$ & 12,000 & 19,200 & 230.4 & 8.0 \\
\hline Diesel bus & 4,000 & 57,600 & 230.4 & 4.8 \\
\hline Diesel Truck & 5,000 & 64,000 & 320.0 & 2.4 \\
\hline 3-wheeler Vehicle & 14,500 & 38,400 & 556.8 & 2.4 \\
\hline 2-wheeler Vehicle & 73,500 & 10,000 & 735.0 & 35.0 \\
\hline
\end{tabular}

By accessing lead $(\mathrm{Pb})$ the lungs and the blood, lead may cause immense neurological damage as well as it affects renal function, cardiovascular diseases, and reproductive system. According to DoE sources, a sharp increase in the number of vehicles and construction sites in 2014-2018 led to the extreme deterioration of air quality in Dhaka.

The industrial sources include brick kilns, fertilizer factories, sugar, paper, jute, and textile mills, spinning mills, tanneries, garment, bread, and biscuit factories, chemical and pharmaceutical industries, cement production and processing factories, metal workshops, wooden dust from saw mills and dusts from plowed, and salt particles from ocean waves near the and coastal areas. These sources produce an enormous amount of black smoke, fumes, gases, and dusts, which create the condition for the formation of fog and smog. Some industries in Bangladesh, such as tanneries in Dhaka City, emit hydrogen sulfide, ammonia, chlorine, and some other odorous chemicals that are poisonous and cause irritation, and public complaints. Those may cause headaches, and other health problems. So, the concern authorities should take the initiative to reduce air pollution in Dhaka city.

Table 3: Effects of Air Pollution on Human Health

\begin{tabular}{|l|l|}
\hline \multicolumn{1}{|c|}{ Substance } & \multicolumn{1}{c|}{ Effect } \\
\hline $\begin{array}{l}\text { Carbon di- } \\
\text { oxide (CO2) }\end{array}$ & $\begin{array}{l}\text { Exposure to CO2 can produce a variety of health effects. These may } \\
\text { include headaches, dizziness, restlessness, a tingling or pins or needles } \\
\text { feeling, difficulty breathing, sweating, tiredness, increased heart rate, } \\
\text { elevated blood pressure, coma, asphyxia, and convulsions }\end{array}$ \\
\hline $\begin{array}{l}\text { Carbon } \\
\text { monoxide (CO) }\end{array}$ & $\begin{array}{l}\text { Breathing CO can cause headaches, dizziness, vomiting, and nausea. } \\
\text { If CO levels are high enough, become unconscious, or die. Exposure to } \\
\text { moderate and high levels of CO over long periods which an increased } \\
\text { risks of heart disease. }\end{array}$ \\
\hline $\begin{array}{l}\text { Hydrocarbons } \\
\text { (HC) }\end{array}$ & $\begin{array}{l}\text { Inhaling low doses causes dizziness, and headache. The exposure of } \\
\text { the human body to significant amounts of these chemical compounds causes } \\
\text { eye irritation, nausea, and dizziness. Long term exposure, in addition to the } \\
\text { carcinogenic effect, can cause skin, liver, kidney, and cataract damage. }\end{array}$ \\
\hline
\end{tabular}




\begin{tabular}{|l|l|}
\hline $\begin{array}{l}\text { Oxides of } \\
\text { nitrogen (NOx) }\end{array}$ & $\begin{array}{l}\text { NOx has direct and indirect effects on human health. It can cause } \\
\text { breathing problems, headaches, chronically reduced the lung function, } \\
\text { eye irritation, loss of appetite, and corroded teeth. Indirectly, it can affect } \\
\text { humans by damaging the ecosystems they rely on in water, and on land- } \\
\text { harming animals. Infants, and children are more susceptible. }\end{array}$ \\
\hline $\begin{array}{l}\text { Particulate } \\
\text { matter 2.5 (PM) }\end{array}$ & $\begin{array}{l}\text { Health effects may include cardiovascular effects such as cardiac } \\
\text { arrhythmias and heart attacks, and respiratory effects such as asthma } \\
\text { attacks and bronchitis. Fine particles (PM2.5) pose the highest health risk. } \\
\text { These fine particles can get deep into the lungs, and some may even get } \\
\text { into the bloodstream. }\end{array}$ \\
\hline Lead (Pb) & $\begin{array}{l}\text { Exposure to high levels of lead may cause anemia, weakness, and kidney } \\
\text { and brain damage. Very high lead exposure can cause death. Lead can } \\
\text { damage a developing baby's nervous system. Even low- } \\
\text { level lead exposures in developing babies to affect behavior, and } \\
\text { intelligence have been found. }\end{array}$ \\
\hline
\end{tabular}

(Source: Effect on Dhaka air quality by 2-strokes engines and suggested remedies. Paper presented by Uttara Motors Ltd. at a Consultative Meeting on an integrated approach to vehicular pollution control held 2015 in Dhaka.)

\section{Air Pollution and Academic Performance}

Air pollution burdens around schools linked to student's health and academic performance. Though it was not conclusively definite cause and effect linkages from macro-level survey, examine associations and rule out prominent confounding variables, such as school demographics, school expenditures, and locations (suburban VS urban) of schools. And can determine how vigorous the associations are, and whether they are a justified concern.

\section{Chemical in the air linked to lower academic performance}

From twelve chemicals, 95\% of the estimated total air pollution concentrations around the schools have noticed. Such as diisocyanates, manganese, sulfuric acid, nickel, chlorine, chromium, trimethylbenzene, hydrochloric acid, molybdenum trioxide, lead, cobalt, and glycol ethers. These chemicals are listed in order, with diisocyanates contributing the most to pollution, and glycol ethers the least. These chemicals come from a variety of sources, including the motor vehicle, steel, and chemical industries, power plants, the manufacturers of rubber and plastic products, and the manufacturers of wood products. The chemicals are led to producing a wide variety of health effects, including increased risk of respiratory, cardiovascular, developmental, and neurological disorders as well as carcinoma. Some of the chemicals, such as lead and manganese, may have direct effects on brain functioning and hence children's ability to perform well in school. However, chemicals that have other health effects, including carcinogens and those that increase the risk of respiratory disorders, may also result in absences from school and otherwise impair students' ability to perform well.

\section{School attendance rates}

Direct measures of health at the level of the individual school are not available in Dhaka, thus used school attendance rates as an alternative for health outcomes. The attendance rates were lower in schools with higher concentrations of pollution around them. This relationship was not linear, so we sorted the schools into quintiles based on the total estimated air pollution concentration within two kilometers. Although attendance rates 
did not vary appreciably for schools in the first two quintiles, we found statistically significant decreases in these rates for schools in the third quintiles.

\section{Student's performance in English and Math}

The next step was to determine whether a relationship existed between pollution levels around the schools and the percentage of students who failed to meet the "Cambridge and National Educational Assessment Program standards" for English and Math. We first examined the overall pattern between pollution levels around the schools and the percentages of students failing to meet the optimum standards. As with attendance rates, we found that this relationship was not linear, so again we looked at quintiles of schools based on the total estimated air pollution concentration within two kilometers. We first examined performance on the English tests. For each grade level for the schools in each quintile of pollution, we determined the average percentage of students who failed to meet the standards. However, there were increases in these percentages for schools in the third quintiles. We next examined performance on the math tests and obtained nearly identical results. We investigated whether these patterns were statistically significant and whether they persisted after we controlled for school attendance rates and school locations, expenditures, and demographics. We used ordinary least squares regression, with the percentages of students in a school failing to meet the state standards in English and math as the dependent variables and dummy variables representing each of the five quintiles of air pollution concentration around the schools as the independent variables.

\section{MAJOR FINDINGS}

For ensuring healthy and potential generation, we need to keep in the account of the following measures for the students to attain the best academic performance. Analyze Potential School Sites:

- The quality of the environment around existing schools should also be evaluated, and steps need to be taken to address unsafe conditions.

- Require Minimum distances Between Schools and Pollution Sources: There should be a minimum distance between sources of pollution and school locations. The locations of existing schools need to be taken into account when considering new highways, industrial facilities, and other potential sources of contamination.

- Adopt Policies to Reduce Exposure: To reduce children's potential exposure to pollution environmental mitigation policies should be adopted. It may be particularly important to implement mitigation approaches in urban settings where land is scarce, and where sites for schools away from sources of pollution are difficult to find.

Student's role in reducing the air pollution:

- $\quad$ Reduce the number of trips they take in your car. Encouraging walking or bicycling.

- Reduce or eliminate using the wood stove.

- Avoid burning leaves, trash, and other materials.

- $\quad$ Limit of using AC and other equipment that emits gas to the atmosphere.

All relevant national, state, and local stakeholders-including school administrators and health officials, parents, teachers, industry and community leaders, public health professionals, and environmental scientists need to work together to develop policies that will ensure safe learning environments for schoolchildren. In cities such as Dhaka, school districts are mainly responsible for deciding where to build new schools. However, 
cooperation between the government and school authorities demonstrates that different levels of social workers or NGOs can work together on these issues. Indeed, they must, if we are to protect the health and enhance the learning environment of the nation's children.

\section{CONCLUSION}

Our findings show that schools in Dhaka disproportionately located in places with high levels of air pollution from industrial sources directly linked to lower grades in academic performance due to air pollution- related illnesses. Furthermore, schools located in areas with the highest pollution levels also had the lowest attendance rates and the highest proportions of students failing to meet the National and International educational testing standards. Future studies should include variables such as parental education levels, social differences, versus artificial light, and ventilation in the classroom, which might influence children's school performance as well. Students are required to attend school and have no choice where they live or go to school, which makes them particularly dependent on governmental policies to protect them from harm. There is a need for proactive school policies that will protect children from exposure to unhealthy levels of air pollution and other environmental hazards. To achieve that goal, we make four policy recommendations, which we discuss in turn: site analysis, minimum distance requirements, environmental mitigation, and multilevel cooperation. Bangladesh has no detail air quality regulations based on which Environmental Impact Assessment. Very few assessments have been done on air quality measurements and national air pollutants estimate. Suggested the following recommendations be implemented to secure the nation, to save our future generation:

- A national committee constituting environment experts need to establish urgently to cope with the problem.

- Approachable guidelines for city planners, traffic engineering practitioners towards mitigating traffic pollution problems and make recommendations for setting National Air Quality Standard.

- Auto-rickshaw (AR) needs to be restricted in Dhaka city.

- The recent initiative of the cab service is appreciating; however, all the diesel vehicles should be banned.

\section{REFERENCES}

ADB, 2006; December Country synthesis report on urban air quality management Bangladesh.

Ahmed, S. and, I. Hossain. 2008. "Applicability of air pollution monitoring in a cluster of brickfield in Bangladesh."

Air Pollution Reduction Strategy for Bangladesh, Final Report. 2012. Department of Environment, Government of Bangladesh in association with Department of Civil Engineering, Bureau of Research, Testing and Consultation, Bangladesh University of Engineering and Technology.

Bearer CF. How are children different from adults? Environ Health Perspect. 1995; 103 (Suppl 6): 7-12.

Brulle RJ, Pellow DN. Environmental justice: human health and environmental inequalities. Annu Rev Public Health. 2006; 27:103-24

Calderón-Garcidueñas L, Franco-Lira M, Torres-Jardón R, HenriquezRoldán C Barragán-Mejía G, Valencia-Salazar G, et al. Pediatric respiratory and systemic effects of chronic air pollution exposure: nose, lung, heart, and brain pathology. Toxicol Pathol. 2007; 35(1):154-62.9 Sunyer J. The neurological effects of air pollution in children.

Calderón-Garcidueñas L, MoraTiscareño A, Ontiveros E, GómezGarza G, Barragán-Mejía G, Broadway J, et al. Air pollution, cognitive deficits, and brain abnormalities: a pilot study with children and dogs. Brain Cogn. 2008; 68(2): 117-27. 
Environmental Protection Agency. Assessing outdoor air near schools [Internet]. Washington (DC): EPA; [last updated 2010 Dec 20; cited2011 Apr 7]. Available from: http://wwww.epa.gov/schoolair]

Environmental Protection Agency. School siting guidelines [Internet].Washington (DC): EPA; 2010 Nov [cited 2011 Jan 2]. It is available from: http://www.epa.gov/schools/siting/

European Environment Agency (EEA). Europe's Environment. The Dobric's Assessment, Copenhagen, Denmark EEA, 1995.

Fischbach S. Not in my schoolyard: avoiding environmental hazards at school through improved school site selection policies [Internet]. Providence (RI): Rhode Island Legal Services; 2006 Mar [cited 2011 Apr 7]. It is available from: http://www .childproofing.org/school_siting_50_state.htm

Hula RC, Bromley-Trujillo R. Cleaning up the mess: redevelopment of urban brownfields. Econ Develop Quart. 2010; 24 (3): 276-87.

JOL, A. \& KIERLAND, G., ED. Air pollution Europe in 1997. Executive summary (http://www.eea.eu.int/Document/Monogr/air97/default.htm). Copenhagen, European Environment Agency, 1997 (EEA Environmental Monograph, No. 4).

Landrigan PJ, Trasande L, ThorpeLE, Gwynn C, Lioy PJ, D'Alton ME, et al. The national children's study: a21-year prospective study of 100,000American children. Pediatrics. 2006, 118(5): 2173-86

Mohai P, Pellow DN, Roberts JT. Environmental justice, 2009; 34:405-30.

Norton RK Planning for school facilities: school board decision making, and local coordination in Michigan. J Plann Educ Res. 2007; 26(4): 478-96.

Pastor M, Morello-Frosch R, Sadd J. Breathless: pollution, schools, and environmental justice in California. Policy Stud J. 2006; 34(3): 337-62.

Suglia F, Gryparis A, Wright RO, Schwartz J, Wright RJ. Association of black carbon with cognition among children in a prospective birth cohort study. Am J Epidemiol. 2008; 167(3):280-6.

Wang S, Zhang J, Zeng X, Zeng Y, Wang S, Chen S. Association of traffic-related air pollution with children's neurobehavioral functions in Quanzhou, China. Environ Health Perspect. 2009;117(10): 1612-8.

WHO. 2005. Air Quality Guidelines Global Update. Particulate matter, ozone, nitrogen Dioxide, and sulfur dioxide. 